\title{
Understanding Academic Misconduct
}

Julia M. Christensen Hughes

University of Guelph

Donald L. McCabe

Rutgers University

\begin{abstract}
Research suggests that the majority of U.S. undergraduate students have engaged in some form of misconduct while completing their academic work, despite knowing that such behaviour is ethically or morally wrong. U.S.-based studies have also identified myriad personal and institutional factors associated with academic misconduct. Implicit in some of these factors are several institutional strategies that may be implemented to support academic integrity: revisiting the values and goals of higher education, recommitting to quality in teaching and assessment practice, establishing effective policies and invigilation practices, providing educational opportunities and support for all members of the university community, and using (modified) academic honour codes. There is a dearth of similar research in Canada despite growing recognition that academic misconduct is a problem on Canadian campuses. This paper suggests that Canadian higher education can learn much from the U.S. experience and calls for both a recommitment to academic integrity and research on academic misconduct in Canadian higher education institutions.
\end{abstract}

\section{RÉSUMÉ}

La littérature suggère que la majorité des étudiants de premier cycle aux États-Unis ont pratiqué au moins une forme de malhonnêteté académique dans la préparation de leur travail universitaire, et ce bien qu'ils sachent qu'un tel comportement contrevient à l'éthique 
et à la morale. Les recherches américaines ont également identifié de nombreux facteurs personnels et institutionnels associés aux conduites inappropriées. Ces facteurs sont implicitement reliés à plusieurs stratégies institutionnelles qui peuvent être appliquées pour soutenir la probité intellectuelle: mettre à jour les valeurs et les buts de l'enseignement supérieur, renouveler l'engagement envers la qualité de l'enseignement et de l'évaluation, établir des politiques et des pratiques de surveillance efficaces, offrir un soutien à tous les membres de la communauté universitaire et utiliser des codes d'honneur universitaire modifiés. Au Canada, malgré l'identification de problèmes de probité intellectuelle sur les campus, il y a pénurie de recherche sur ce sujet. Cet article suggère que l'enseignement supérieur canadien a beaucoup à apprendre de l'expérience américaine et lance un appel favorable tant à un renouveau de l'engagement envers la probité intellectuelle qu'à un accroissement de la recherche sur ce sujet dans les institutions canadiennes d'enseignement supérieur.

\section{INTRODUCTION}

Based in part on a growing body of primarily U.S.-based research that suggests academic misconduct has become commonplace amongst the majority of college and university students and on growing numbers of incidents on their own campuses, Canadian universities have begun to identify academic misconduct as a potential area of concern. Drawing on the U.S. experience, this paper suggests that Canadian higher education has much to learn from its American counterpart. In this paper, we begin by defining academic integrity and argue that Canadian institutions must recommit to upholding this essential value. We also discuss the extent to which academic misconduct has been found to occur in American colleges and universities and review a variety of individual and institutional factors found to be associated with academic misconduct. Based on these factors, we suggest strategies that colleges and universities might adopt to encourage academic integrity on their own campuses. Finally, we call for further research on academic misconduct within Canadian higher education.

\section{Academic Integrity and the Aims of Higher Education}

The terms academic dishonesty and academic misconduct are often used interchangeably in reference to a range of unethical behaviours in which some students engage while completing their academic work. In an article in University Affairs, Mullens (2000) defines academic dishonesty as

anything that gives a student an unearned advantage over another. It includes any of the following: purchasing an essay; plagiarizing paragraphs or whole texts; impersonating another to take a test; sneaking a peek at another student's answers; smuggling crib notes into 
a test; padding a bibliography; fudging laboratory results; collaborating on an assignment when the professor asks for individual work; or asking for a deadline extension by citing a bogus excuse. (p. 23)

Academic misconduct may also include forging or altering university documents (e.g., grade transcripts), writing a paper for another student, and hiding or damaging library resources.

Academic integrity, however, is more than the absence of misconduct, but rather "a commitment, even in the face of adversity, to five fundamental values: honesty, trust, fairness, respect, and responsibility" (The Fundamental Values of Academic Integrity, 1999, p. 4). Such values should arguably underpin all academic work and be rigorously promoted and upheld.

Some have argued that, in addition to espousing and practicing integrity, education should also be concerned with the development of character and citizenship behaviours. According to Lickona (1991), "wise societies since the time of Plato...have educated for character as well as intellect, decency as well as literacy, virtue as well as knowledge" (p.6). Quoting Theodore Roosevelt, Lickona (1991) also suggested, "To educate a person in mind and not in morals is to educate a menace to society" (p.3).

Similarly, Returning to our roots: A learning society, a U.S.-based report by the Kellogg Commission (1999) argued that it is imperative that the U.S. become a learning society for both economic prosperity and social good. Furthermore, the Commission suggested that higher education has an essential role to play in the creation of a learning society, including the development of citizenship behaviours.

Recently, similar sentiments have also been voiced in Canada. In a Globe and Mail article, Fraser (2005), citing a submission by George Fallis to the recent Rae Report on post-secondary education in Ontario, argued that universities should be judged, in part, by their "service to democratic society as critic, conscience and public intellectual and by their preparation of students for citizenship" (p.9).

Unfortunately, as elaborated in the next section, studies conducted over the past 50 years have brought into question how successful most American colleges and universities have been in promoting integrity and building character. Results of U.S.-based studies have consistently shown that many students engage in academic misconduct in the completion of their academic work and that academic institutions and faculty have done little about it (see for example, Bowers, 1964; Hetherington \& Feldman, 1964; Singhal, 1982; McCabe, \& Trevino, 1993, 1996; Payne \& Nantz, 1994; McCabe, Trevino, \& Butterfield, 1999, 2001). What is not clear is to what extent the same is true in Canada.

\section{Rates of Engagement in Academic Misconduct}

Purportedly, academic misconduct has always been with U.S.. It has been described in the higher education literature as "ubiquitous" (Pincus \& Schmelkin, 2003); as an "epidemic" (Haines, Diekhoff, LaBeff, \& Clark, 1986, 
p.342), a "perennial problem" (Davis, Grover, Becker, \& McGregor, 1992, p.16), and "one of the major problems in education today" (Singhal, 1982, p.775). Such observations are primarily based on studies of undergraduate students at U.S. colleges and universities (both private and public), using a variety of data collection techniques (e.g., self report surveys, in-depth interviews, experiments), and differing sample sizes (e.g., from less than one hundred students in a single department to thousands of students on multiple campuses).

Although they vary in methodology, these studies have consistently found that the majority of undergraduate students have engaged in some type of misconduct in the completion of their academic work. For example, in Bower's (1964) seminal multi-campus study involving over 5000 students from 99 U.S. campuses, three out of four students reported engaging in at least one of 13 questionable academic behaviours, with 39\% of students reporting having engaged in "serious test cheating" (e.g., copying during an exam with or without the other student's knowledge, using crib notes, helping someone else to cheat on a test or exam) and 65\% reporting having engaged in "serious cheating on written work" (e.g., plagiarism, fabricating or falsifying a bibliography, turning in work done by someone else, copying a few sentences of material without footnoting).

In a similar 1990-1991 study involving over 6,000 students across 31 small to medium sized U.S. campuses, McCabe and Trevino (1993) found that as many as two out of three students reported engaging in at least one of 14 questionable behaviours and that almost $20 \%$ of students reported engaging in 5 or more such behaviours. In this case, $64 \%$ of students were found to have engaged in serious test cheating and 66\% in serious written cheating.

Smaller, single campus studies have also reported high rates of academic misconduct. For example, Hetherington and Feldman (1964) used an experimental design in which 78 psychology students at one U.S. state university were presented with multiple opportunities to cheat on actual course exams. More than half (59\%) of the students exhibited some form of cheating, the vast majority (87\%) of whom were observed to cheat multiple times. Payne and Nantz (1994) used in-depth interviews to study the cheating behaviours of 22 business students in a medium-sized, U.S., state university. Nineteen (or 86\%) of the students admitted to having cheated in their college work. Finally, Singhal (1982) surveyed 364 engineering students at a U.S. state university; 56\% of students reported having cheated.

What is particularly striking about these high rates of engagement is that they occurred despite student recognition that such behaviour is morally wrong. In Bower's study, for example, $80 \%$ of students agreed or strongly agreed that: "students are morally obliged not to cheat"; "under no circumstances is cheating justified"; and, "cheating directly contradicts the goals of education" (1966, p. 21). Similarly, Singhal (1982) found that over 85\% agreed "cheating is wrong, dishonest, or unethical" and, consistent with this view, 58\% said they felt "guilty after cheating" (p. 776). 


\section{Why Academic Misconduct Occurs}

If students know cheating is wrong and feel guilty about doing it, why do so many students engage in it? Myriad personal and institutional factors have been found to be associated with academic misconduct and provide possible explanations. These factors also point to possible interventions for discouraging academic misconduct and encouraging integrity.

\section{Personal Factors}

Many studies (e.g., Aronson \& Mettee, 1968; Bowers, 1964; Davis, Grover, Becker, \& McGregor, 1992; Davis \& Ludvigson, 1995; Eisenberger \& Shank, 1985; Haines et al. 1986; Hetherington \& Feldman, 1964; Johnson \& Gormly, 1971; McCabe \& Trevino, 1993, 1997; McCabe, Trevino, \& Butterfield, 1999, 2001; Smith, Ryan, \& Diggins, 1972; Steininger, Johnson, \& Kirts, 1964; Ward, 1987) have sought to identify personal factors associated with student cheating and a number of variables have been generally found to be significant.

Personal factors found to be associated with lower levels of student cheating include (1) demographic factors (e.g., age - older; gender - female; marital status - married; year level - higher; GPA - mid range; first born; financially self-supporting; employment status - full time); (2) self-reported behaviours (e.g., less cheating in high school, better study habits, less church attendance, less involvement in intramural or intercollegiate sports and other extra curricular activities); and (3) attitudes (e.g., stronger work ethic, greater self esteem, lower test anxiety, lower willingness to risk detection, more prone to feelings of guilt).

Other research has suggested that views on plagiarism, particularly when influenced by national culture and language, may also be important personal factors. Several authors have argued that plagiarism is a Western notion based on intellectual property considerations and individualistic cultural norms which students from collectivist cultures may have difficulty accepting (Scollon, 1995; Pennycook, 1996; Myers, 1998). Research has also suggested those writing in a second language may experience difficultly avoiding plagiarism. Second language writers employ a variety of strategies (e.g., copying expressions, imitating sentence structures, paraphrasing superficially) to assist them in their writing; some of these practices may contravene plagiarism policies (Myers, 1998; Percorari, 2000). Silva (1993) concluded that holding second language writers accountable to the same standards as first language writers is inappropriate.

In summary, maturity, habit, attitude, culture and first-language are among the personal factors which explain some of the reasons why students may engage in various behaviours that may be commonly perceived as academic misconduct. 


\section{Institutional and Contextual Factors}

A variety of institutional and contextual factors has also been found to be statistically associated with student cheating (e.g., Bowers, 1964; McCabe \& Trevino, 1993, 1996; McCabe, Trevino, \& Butterfield, 1999, 2001). Factors associated with lower rates of student cheating include the following: smaller institutional size, existence of an honour code, student understanding and acceptance of academic misconduct policies, severity of penalties for students found responsible for cheating, peer disapproval of cheating, certainty of being report by a peer, and peers' cheating behaviours.

Many of these factors are arguably associated with student risk perception (risk of being caught and the severity of possible punishments). Unfortunately, research suggests that many students perceive little risk for engaging in academic misconduct and further, that theses perceptions are well founded. For example, in one study Haines et al. (1986) found that while 54\% of students reported have engaged in at least one type of academic misconduct during the past year, only $1 \%$ reported having been caught. In another study, Jendrek (1992) found that of the approximately 76\% of students who indicated they had witnessed examination-based cheating, only $1 \%$ had reported it, despite an institutional policy requiring them to do so.

Students are also greatly influenced by their perceptions of peer behaviour. Of all the institutional variables they explored, McCabe and Trevino (1993) found that perceptions of peers' cheating behaviours had the strongest association with student cheating levels. They suggested that not only does peer cheating provide a normative model condoning academic misconduct, but honest students may also feel that if others are cheating and not being caught, they may have no choice but to cheat as well to remain competitive. McCabe and Trevino (1993) concluded,

the most important question to ask. . . may be how an institution can create an environment where academic dishonesty is socially unacceptable, that is, where institutional expectations are clearly understood and where students perceive that their peers are adhering to these expectations. ( p. 534)

Administrators and faculty arguably play an essential role in creating such an environment. In reflecting on institutional factors associated with academic misconduct on his own campus and the lack of commitment to dealing with them, Pavela (1981) observed,

the incentives to engage in academic dishonesty on our campus included a lack of attention to even rudimentary precautions in the preparation and proctoring of examinations, vague and cumbersome policies and procedures that discouraged faculty members from reporting cases, 
and lenient penalties that suggested to the campus community that academic dishonesty was not regarded as a serious offence... Academic dishonesty does indeed reveal the moral deficiencies of those students who engage in it. Responsibility also lies, however, with administrators and faculty members who knowingly tolerate conditions that would allow academic dishonesty to flourish in any generation of students. (p. 64)

Other research confirms Pavela's observations that administrators and faculty could do much more to encourage academic integrity. In a survey of 175 senior university administrators involved in student and academic affairs (Aaron \& Georgia, 1994), only slightly more than 50\% felt their institution had made an extensive commitment to addressing academic misconduct. In another study, Kibler (1994) found that although many institutions disseminated academic dishonesty policies to faculty, staff and students (over 80\%) and discussed them during new student orientation (69\%), only half discussed academic integrity during new faculty orientation (51\%) or offered specific training sessions on academic integrity/misconduct to course instructors (46 percent). Even fewer discussed it as part of TA orientation (24\%) or general faculty training programs (21\%). Kibler (1994) concluded,

systematic, comprehensive programs to promote academic integrity are not prevalent in higher education institutions. Their absence fails to foster the awareness of academic dishonesty among students and faculty that is a necessary part of an effective prevention strategy. . . Faculty are the most critical persons on campus in preventing academic dishonesty. .. If they are isolated from an institutions' efforts to prevent dishonesty, those efforts will likely be ineffective. (p.100-101)

In questioning why this is the case, Alschuler and Blimling (1995) wrote,

the mystery is not why cheating is wrong or why students cheat, but why there is so little passion about this massive assault on the highest values of the academy. Why no high profile investigations, and emergency programs to restore academic integrity? (p. 124)

Offering one possible explanation for the lack of such systematic, comprehensive programs on many campuses, Besvinick (1983) suggested that influenced by "time constraints, financial problems, governmental regulations, and other social pressures" universities have made decisions "not consonant with a position of integrity" (p. 569). We believe institutions must address this gap and agree with Kibler that the faculty role will be critical in creating institutional environments that encourage integrity. 


\section{Faculty Attitudes and Behaviours}

Further supporting student perceptions that there is little risk in cheating, research suggests that many faculty fail to penalize students or follow institutional policy when cheating does occur. For example, McCabe (1993) reported that between 47 and 60\% of faculty go "to little or very little effort to document an incident" (p. 343) of academic misconduct. Similarly, Jendrek (1989) found that of the $60 \%$ of faculty who said they had witnessed student cheating, only $65 \%$ had penalized the student and, contrary to university policy, only $20 \%$ had formally reported the incident. Interestingly, in Jendrek's study, non-tenured faculty were found to be statistically less likely to penalize students for academic misconduct than tenured faculty.

Jendrek (1989) noted several problems with faculty ignoring misconduct or taking matters into their own hands, including placing honest students at a competitive disadvantage, denying the accused student due process, hampering the identification of repeat offenders, and sending the message that cheating is not taken seriously. Similarly, McCabe and Pavela (1998) suggested, "those who ... look the other way when students engage in academic dishonesty, alienate honest students and foster a climate of moral cynicism on campus" (p. 101). They also "send the message that a core value of academic life, honesty, is not worth any significant effort to enforce" (Mullens, 2000, p. 26).

The literature provides several possible explanations for faculty reluctance to deal with academic misconduct (Alschuler \& Blimling, 1995; Pavela, 1997; Schneider, 1999). One is a lack of buy-in to formal policies and procedures. Faculty who perceive the process too cumbersome, the penalties inappropriate, or a lack of institutional support for cases brought forward are more likely to do nothing or negotiate a private agreement with the student. According to Alschuler and Blimling (1995), faculty do their "own cost/benefit analysis" and many decide to look the other way (p. 124). Factors faculty may take into consideration include the perceived time and effort required (in a system that primarily rewards research and publication) as well as potential personal costs such as the discomfort caused by confronting a student about an ethical issue, or more serious outcomes associated with litigation, harassment, or being blamed by the administration for the situation (Alschuler \& Blimling, 1995; Pavela, 1997; Schneider, 1999).

In addition to how they respond to incidents of academic misconduct when they do arise, the behaviour of faculty with respect to teaching and assessment practice has also been found to have an effect. For example, Cole and Kiss (2000) suggested that "students are most likely to cheat when they think their assignments are pointless, and less likely to cheat when they admire and respect their teachers and are excited about what they are learning" (p. 6-7).

Supporting this perspective, Steininger, Johnson and Kirts (1964) surveyed 49 psychology students at one U.S. university and found an association between four student attitudes and behaviours (i.e., justification for cheating; urge to cheat; actual copying, and letting others copy) and four course-related factors 
(divided into negative and positive components): (1) interest level in course content - course meager and uninteresting or course new and interesting; (2) quality of teaching - professor poor or professor good; (3) test meaningfulness - test based on senseless detail or test sensible and meaningful; and (4) test difficulty - test hard or test easy.

Students were presented with a variety of situations, each which contained either the negative or positive descriptor of each of the four factors (i.e., the number of negative components in each situation ranged from zero to four). Steininger et al. (1964) found that as the number of negative descriptors increased, all of the student attitudes and behaviours (i.e., justification for cheating; urge to cheat; actual copying, and letting others copy) increased "sharply and consistently" (p. 321).

Steininger et al.'s study was replicated by Johnson and Klores (1968), who surveyed 78 psychology students at the same university. In this case, however, students were divided into two groups - one was told that cheating on campus was rare, while the other group was told that cheating on campus was prevalent. Once again, all attitudes and behaviours - justification to cheat, urge to cheat, actual copying, and letting others copy - increased with the number of negative course components. Interestingly, however, students who were told cheating was rare reported significantly lower scores than those who were told cheating was prevalent, suggesting that the impact of negative course attributes on student cheating may be influenced by perceptions of peers' behaviours.

In summary, from an institutional perspective, underlying student-cheating behaviours are a variety of factors including perceptions of risk and peers' behaviours, institutional commitment to developing comprehensive and effective policies and invigilation (proctoring) practices, the provision of educational opportunities for faculty and students, faculty and TA knowledge and support

of policies and procedures, and the overall quality of the curriculum, including the quality of teaching and assessment practice.

\section{Institutional Strategies to Encourage Academic Integrity}

As previously argued, integrity is an essential value of academe. Given the extent to which academic misconduct reportedly occurs, despite student awareness that such behaviour is morally wrong, and the myriad factors associated with increased levels of student engagement (i.e., personal factors, institutional and contextual factors, faculty behaviour and attitudes), promoting and upholding academic integrity clearly requires a comprehensive approach, supported at the highest levels and throughout the institution. As Alschuler and Blimling (1995) argued, "curbing epidemic cheating requires seeing it as a systemic problem, understanding what blocks solutions, and taking collaborative action to transform the system" (p. 123).

McCabe and Pavela suggest the following 10 principles, or elements of such an approach, for fostering academic integrity and transforming institutions (Pavela, 1997): 1) affirm the importance of academic integrity; 2) foster a love 
of learning; 3) treat students as ends in themselves; 4) foster an environment of trust in the classroom; 5) encourage student responsibility for academic integrity; 6) clarify expectations for students; 7) develop fair and relevant forms of assessment; 8) reduce opportunities to engage in academic misconduct; 9) challenge academic dishonesty when it occurs; and 10) help define and support campus-wide academic integrity standards. The Centre for Academic Integrity at Duke University actively promotes these principles.

Within Canada, such action might best begin by affirming not only the values and goals of higher education, including the importance of academic integrity, but also perhaps the character development and citizenship behaviours of students. By acknowledging these latter outcomes, the moral development of students becomes an explicit concern, one the curriculum would need to purposefully and thoughtfully address.

As previously suggested, academic integrity also needs to be supported by a renewed focus on the quality of the educational experience. According to Davis, Grover, Becker, and McGregor (1992), what is needed is a "stronger commitment to the educational process" (p. 19). Within Canada, enhancing the quality of teaching and learning in higher education will require strong leadership as well as the explicit recognition from all major stakeholders (e.g., governments, administrators, faculty, parents, students, employers) that change is required. This will be helped if the perceived prestige and financial implications of teaching becomes better balanced with the research agenda. Unfortunately, given the financial pressures that educational institutions are faced with today, as long as research activity is perceived as a revenue stream and teaching as a cost, research will continue to garner more prestige and be placed as a higher priority than teaching (Christensen Hughes \& Rog, 2006).

Enhancing the quality of teaching and learning also requires that more attention be given to the training and development of TAs, PhD students, and faculty members with respect to pedagogical and assessment practice. For example, as long as $\mathrm{PhD}$ programs remain focused almost exclusively on preparing future academics for their research responsibilities, with little if any attention being paid to their teaching roles, this inequity will remain entrenched. Institutional integrity is arguably brought into question when faculty are assigned responsibility to teach and assess student work without adequately preparing them for this important work. Further, selection, promotion and tenure processes need to be revised so that teaching and its scholarship are appropriately assessed and rewarded. It is not yet clear whether sufficient support exists to make such broad based change possible.

Finally, academic integrity needs to be supported by the development of systems and a campus climate or culture that demands integrity by all members of the university community. Institutions should revisit their academic integrity policies and invigilation practices and ensure they have the support of administrators, faculty, and students. They must also communicate these policies and practices broadly and educate all members of the university community about their importance. Drawing on the personal factors previously discussed, 
focused educational programming may be particularly important for younger (e.g., first and second year) students. As an example, over the past few years several Canadian universities have introduced "Academic Integrity Awareness" weeks as part of their fall orientation activities. International students, as well as those studying in a second language, may also benefit from sessions customized to their needs. Faculty and TAs should be encouraged to support these efforts by clarifying their expectations with their students, explaining why academic integrity is important, following up with academic misconduct when it does occur, and, perhaps most importantly, modelling academic integrity in their own practice. Mechanisms for supporting faculty who bring suspected cases of academic dishonesty forward should also be established. Several Canadian universities have recently created academic integrity offices that provide such support. Publicizing statistics of the outcomes of academic misconduct cases can also help send the message that there are real consequences for engaging in such behaviour. Canadian universities may also wish to learn more about modified honour codes, a strategy gaining some popularity in the U.S.. Modified honour codes place greater responsibility on students for promoting and maintaining a culture of academic integrity on campus and preliminary data supports the belief that such responsibility can lead to reduced levels of academic dishonesty among students (McCabe \& Pavela, 2000).

In summary, U.S.-based research suggests that effectively addressing academic misconduct requires a multi-faceted approach. Within Canada, such an approach should include a review of what the values and goals of Canadian higher education should be, a recommitment to quality in teaching and assessment practice, the establishment of effective policies and invigilation practices, and buy-in and support of all members of the university community.

This review raises several implications for Canadian higher education institutions. While we can learn much from the American experience, in particular the suggestions outlined above, a truly comprehensive study of academic misconduct in Canada is needed. Although the authors have gathered data that will be of some use in this regard, more detailed studies are needed. A better understanding of the unique characteristics of the Canadian higher education system may be instructive in tailoring institutional strategies appropriate for promoting academic integrity in Canadian colleges and universities. Finally, we need to identify how Canadian colleges and universities are responding to academic misconduct when it does occur and what strategies have proven most successful.

As previously argued, higher education plays an essential role in democratic society - one that requires U.S. to provide our students with a high quality education, to develop moral and engaged citizens, and to uphold the highest standards of integrity. We need a total recommitment to this role. Discovering the extent to which academic misconduct is occurring on our own campuses and how faculty and TAs respond when they encounter it will be an important part of this process. 


\section{REFERENCES}

Adams, M. (2003). Fire and ice: United States, Canada and the myth of converging values. Toronto, ON: Penguin Canada.

Aaron, R.M., \& Georgia, R.T. (1994). Administrator perceptions of student academic dishonesty in collegiate institutions. NASPA Journal, 31(2), 83-91.

Alschuler, A.S., \& Blimling, S.B. (1995). Curbing epidemic cheating through systemic change. College Teaching, 43(4), 123-125.

Aronson, E., \& Metee, D.R (1968). Dishonest behaviour as a function of differential levels of induced self-esteem. Journal of Personality and Social Psychology, 9(2), 121-127.

Besvinick, S.L. (1983). Integrity and the future of the university. Journal of Higher Education, 54(5), 566-573.

Bowers, W.J. (1964). Student dishonesty and is control in college. New York, NY: Bureau of Applied Social Research, Columbia University.

Bowers, W.J. (1966). Cheating on the college campus. NEA Journal, 55(2), 21-22.

Christensen Hughes, J. \& Rog, E. (2006). Roundtable on research, teaching and learning. University of Guelph. Unpublished conference report.

Cole, S., \& Kiss, E. (2000). What can we do about student cheating? About Campus, 5, 5-12.

Davis, S.F., Grover, C.A., Becker, A.H., \& McGregor, L.N. (1992). Academic dishonesty: Prevalence, determinants, techniques, and punishments. Teaching of Psychology, 19(1), 16-20.

Davis, S.F., \& Ludvigson, H.W. (1995). Additional data on academic dishonesty and a proposal for remediation. Teaching of Psychology, 22(2), 119-121.

Eisenberger, R., \& Shank, D.M., (1985). Personal work ethic and effort training affect cheating. Journal of Personality and Social Psychology, 49(2), 520-528.

Fraser, J. (2005). Universities need money, yes, but a social mission, too. March 26, F9.

Haines, V.J., Diekhoff, G.M., LaBeff, E.E., \&, Clark, RE., (1986). College cheating: Immaturity, lack of commitment and the neutralizing attitude. Research in Higher Education, 25(4), 342-354.

Hetherington, E.M., \& Feldman, S.E., (1964). College cheating as a function of subject and situational variables. Journal of Educational Psychology, 55(4), 212-228. 
Jendrek, M.P. (1989). Faculty reactions to academic dishonesty. Journal of College Student Development, 30, 401-406.

Jendrek, M.P. (1992). Students' reactions to academic dishonesty. Journal of College Student Development, 33, 260-273.

Johnson, C.D. \& Gormly, J. (1971). Achievement, sociability, and task importance in relation to academic cheating. Psychology Reports, 28, 302.

Johnson, R.E., \& Klores, M.S. (1968). Attitudes towards cheating as a function of classroom dissatisfaction and peer norms. Journal of Educational Research, 62(2), 60-64.

Kellogg Commission on the Future of State and Land-Grant Universities. (September, 1999). Returning to our Roots: A learning society. (Fourth Report). Washington, DC: National Association of State Universities and LandGrant Colleges. http://www.nasulgc.org/publications/Kellogg/Kellogg1999_ LearnSociety.pdf. Accessed June 23, 2006.

Kibler, W.L. (1993). A framework for addressing academic dishonesty from a student development perspective. NASPA Journal, 31(1), 8-18.

Kibler, W.L. (1994). Addressing academic dishonesty: What are institutions of higher education doing and not doing? NASPA Journal, 31(2), 92-101.

Lickona. T. (1991). Educating for character: How our schools can teach respect and responsibility. New York, NY: Bantam Books,

McCabe, D. (1993). Academic integrity: What the latest research shows. Synthesis: Law and Policy in Higher Education, 5, 340 - 343.

McCabe, D.L., \& Cole, S. (1995). Student collaboration: Not always what the instructor wants. American Association for Higher Education Bulletin, 48, 3-6.

McCabe, D.L., \& Pavela, G.M. (1998). The effect of institutional policies and procedures on academic integrity. In, D. D. Burnett, L. Rudoph, and K.O. Clifford (Eds.), Academic integrity matters. National Association of Student Personnel Administrators. Monograph 20, 93-108.

McCabe, D.L., \& Pavela, G.M. (2000). Some good news about academic integrity. Change, 33(5), 32-38.

McCabe, D.L., \& Trevino, L.K. (1993). Academic dishonesty: Honor codes and other contextual influences. Journal of Higher Education, 64(5), 522538.

McCabe, D.L., Trevino, L.K. \& Butterfield (1999). Academic integrity in honor code and non-honor code environments: A qualitative investigation. Journal of Higher Education, 70(2), 211-234.

McCabe, D.L., Trevino, L.K., \& Butterfield, K.D. (2001). Cheating in academic institutions: A decade of research. Ethics \& Behaviour, 11(3), 219-233. 
Mullens, A. (2000, December). Cheating to win. University Affairs, 22-28.

Myers, S. (1998). Questioning author(ity): ESL/EFL, science, and teaching about plagiarism. TESL-EJ, 3(2), 1-15.

Pavela, G. (1981, February 9). Cheating on campus: Who's really to blame? Chronicle of Higher Education, 64.

Pavela, G. (1997). Applying the power of association on campus: A model code of academic integrity. Journal of College and University Law, 24(1), 97118.

Payne, S.L., \& Nantz, K.S. (1994). Social accounts and metaphors about cheating. College Teaching, 42(3), 90-96.

Pecorari, D. (2000). Plagiarism in academic writing. Presented at the Navigating the New Millennium, $34^{\text {th }}$ annual TESOL conference, March $14-18$, Vancouver, BC.

Pincus, H.S., \& Schmelkin, L.P. (2003). Faculty perceptions on academic dishonesty. Journal of Higher Education, 74(2), 196-209.

Pennycook, A. (1996). Borrowing other's words: Text, ownership, memory, and plagiarism. TESOL Quarterly, 30(2), 201-230.

Schneider, A. (1999, January 22). Why professors don't do more to stop students who cheat. Chronicle of Higher Education, A8.

Scollon, R. (1995). Plagiarism and ideology: Identity in intercultural discourse. Language in Society, 24(1), 1-28.

Silva, T. (1993). Toward an understanding of the distinct nature of L2 writing: The ESL research and its implications. TESOL Quarterly, 27(4), 657677.

Singhal, A.C. (1982). Factors in students' dishonesty. Psychological Reports, 51(3), 775-780.

Smith, C.P., Ryan, E.R. \& Diggins, D.R. (1972). Moral decision making: Cheating on examinations. Journal of Personality, 40(4), 640-660.

Steininger, M., Johnson, R.E., \& Kirts, D.K. (1964). Cheating on college examinations as a function of situationally aroused anxiety and hostility. Journal of Educational Psychology, 55(6), 317-324.

The Fundamental values of academic integrity (1999, October). The Center for Academic Integrity, Duke University.

Ward, D.A. (1987). Self-esteem and dishonest behaviour revisited. Journal of Social Psychology, 126(6), 709-713. 


\section{CONTACT INFORMATION}

Julia M. Christensen Hughes

University of Guelph

Guelph, Ontario

N1G 2W1

Phone: 519-824-4120 \# 56938

jchriste@uoguelph.ca 